Scientific Electronic Archives

Issue ID: Sci. Elec. Arch. Vol. 14 (10)

October 2021

DOI: http://dx.doi.org/10.36560/141020211424

Article link: https://sea.ufr.edu.br/SEA/article/view/1424

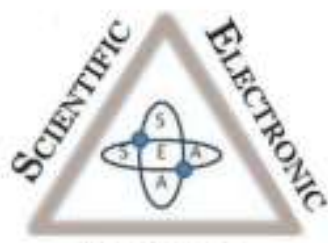

Archives

\title{
Técnicas de secagem de frutas: uma revisão
}

\author{
Techniques of drying fruits: A review
}

\author{
Anny Beatriz Santana e Silva \\ Universidade do Estado de Mato Grosso \\ Eduarda Giardina da Silva \\ Universidade do Estado de Mato Grosso \\ Letícia Rigo \\ Universidade do Estado de Mato Grosso \\ Mayane Prado de Oliveira \\ Universidade do Estado de Mato Grosso \\ Raquel Aparecida Loss \\ Universidade do Estado de Mato Grosso \\ Sumaya Ferreira Guedes \\ Universidade do Estado de Mato Grosso \\ Juliana Maria de Paula \\ Universidade do Estado de Mato Grosso \\ Corresponding author \\ Claudineia Aparecida Queli Geraldi \\ Universidade do Estado de Mato Grosso \\ claudineia.geraldi@unemat.br
}

\begin{abstract}
Resumo. O consumo de frutas, em geral, além de proporcionar ao organismo humano compostos benéficos à saúde, contribui com o fluxo econômico, devido à comercialização das mesmas. No entanto, durante as etapas de cultivo, grandes perdas na produção podem ocorrer. Dessa forma, o uso de técnicas de secagem pode garantir maior conservação das frutas, reduzindo o desperdício e perdas econômicas. Nesse contexto, essa revisão abordou diferentes técnicas de secagem para conservação de frutas, dentre elas: secagem natural, leito fixo, camada de espuma, atomização e por formo micro-ondas. Em cada técnica foram mencionados os princípios, principais parâmetros estudados e os resultados promissores observados. Além disso, é relatada a importância da caracterização físicoquímica e a modelagem matemática dos dados experimentais. A partir dessa revisão, esperamos fornecer um compilado de resultados promissores de diversas técnicas de secagem, para várias frutas estudadas, a fim de favorecer o desenvolvimento de produtos com maior vida de prateleira, com maior retenção de propriedades nutritivas e menor desperdício.

Palavras-chaves: Secagem natural, Leito fixo, Camada de espuma, Atomização, Micro-ondas.
\end{abstract}

Abstract. Consumption of fruits, in general, in addition to providing the human body with compounds beneficial to health, contributes to the economic flow, due to their commercialization. However, during the stages of cultivation, large losses in production can occur. Thus, the use of drying techniques can guarantee greater conservation of the fruits, reducing waste and economic losses. In this context, this review addressed different drying techniques for fruit conservation, among them: natural drying, fixed bed, foam layer, atomization, and a microwave oven. In each technique, the principles, 
main parameters studied, and the promising results observed were mentioned. In addition, the importance of physicalchemical characterization and mathematical modeling of experimental data is reported. From this review, we hope to provide a compilation of promising results from various drying techniques, for various fruits studied, in order to favor the development of products with longer shelf life, with greater retention of nutritional properties and less waste.

Keywords: Natural drying, Fixed bed, Foam mat, Atomization, Microwave.

\section{Contextualização e análise}

Com o objetivo de atender o mercado interno e externo, o Brasil é um dos maiores produtores mundiais de frutas, além disso, destacase pela grande diversidade de frutas, incluindo frutas tropicais e de clima temperado. Logo, a fruticultura tem uma grande importância social, tanto para economia do país quanto para a saúde humana (NEVES, 2018).

Do ponto de vista do valor nutritivo, as frutas são consideradas complementos dos alimentos básicos, fornecendo energia, minerais, vitaminas, fibras e compostos antioxidantes e seu consumo tem aumentado cada vez mais. A comercialização de produtos derivados de frutas em escala mundial se expandiu, principalmente em países em desenvolvimento, como o Brasil, por exemplo. A área da fruticultura brasileira vem crescendo ao longo dos anos, e realizando seus investimentos no aumento da produção, produtividade e melhoria da qualidade de diversos frutos (NEVES, 2018; ALBUQUERQUE et al., 2016; SILVA; FIGUEIREDO; LIMA, 2016).

As frutas são consumidas principalmente de forma in natura, devido suas características como aroma, cor, textura e propriedades nutricionais na forma natural. No entanto, um grande problema enfrentado pelos fruticultores é a conservação destes alimentos maduros, pois, cerca de $40 \%$ é perdido entre a colheita no campo até a chegada ao mercado consumidor, ocasionando perdas nutricionais e aumento de preço para o consumidor (ARAÚJO et al., 2017; BARBOSA et al., 2014).

A perecibilidade das frutas é decorrente da alta atividade de água $(\mathrm{Aw})$ presente neste tipo de alimento, que faz com que sejam mais susceptíveis a atividade microbiana, portanto, técnicas que reduzam e/ou controlem esse parâmetro podem favorecer o aumento da vida de prateleira dos alimentos (CELESTINO, 2010).

A secagem é uma das técnicas de conservação mais antigas, e baseia-se na retirada de água de um produto por evaporação ou sublimação, através da aplicação de calor em condições controladas. (FERREIRA et al., 2014; BALBAY et al., 2012).

No entanto, cada tipo de secagem pode influenciar na qualidade e propriedades físicoquímicas ou nutricionais das frutas, sendo que cada técnica possui suas vantagens e restrições específicas, levando a diferenciação do produto final. Dentre os diversos métodos empregados para secagem de frutas, destacam-se secagem natural, em leito fixo, em camada de espuma, por atomização e em forno micro-ondas (IZLI; IZLI; TASKIN, 2017; AL JUHAIMI et al., 2016).
Assim, o estudo dos processos de secagem fornece informações sobre o comportamento do fenômeno de transferência de calor e massa entre o material biológico e o elemento de secagem, sendo fundamental para projetar equipamentos de secagem, calcular a energia requerida no processo e avaliar a microestrutura e os fenômenos físicos que ocorrem na superfície dos alimentos (FARIA et al., 2012; CORRÊA et al., 2010).

Nesse contexto, esse trabalho teve por objetivo realizar uma revisão bibliográfica sobre as principais técnicas de secagem aplicada à frutas, abordando os fundamentos, vantagens e desvantagens de cada técnica, bem como seus principais parâmetros e resultados na secagem de diversas frutas.

A revisão bibliográfica do presente artigo foi realizada buscando trabalhos acerca da temática de secagem de frutas, na base de dados do Google Acadêmico. O período de busca foi definido de 2011 a 2021.

\section{Secagem natural}

secagem natural é o método mais antigo e amplamente utilizado nos países subdesenvolvidos e/ou em desenvolvimento, faz uso de energia solar para a conservação de alimentos, como grãos, vegetais, frutas, etc. Nesta técnica, as sementes são secadas essencialmente pela ação do calor e do vento, sem uso de equipamento mecânico e/ou eletroeletrônico, sendo mais barata e mais lenta que a artificial. É necessário apenas uso de bandejas e redes protetoras contra insetos, porém, existem secadores naturais que permitem uma proteção maior ao alimento. Este é composto por uma tampa de vidro, para que ocorra a absorção da radiação térmica, e com uma inclinação adequada, que facilite o processo da entrada do ar aquecido (CELESTINO, 2010; MOREIRA et al., 2019).

A Figura 1 exemplifica o processo de secagem natural.

De acordo com Celestino (2010) a secagem natural é mais comum em grãos e castanhas, em virtude de sua superfície de contato não ser diretamente exposta ao ambiente, como no caso das frutas, hortaliças, ervas e carnes. No entanto, alguns estudos recentes relataram 0 uso de secagem natural para conservação de frutas, como mostra a Tabela 1.

Uma das principais vantagens do método é o baixo custo investimento e, ainda assim, obtém-se o prolongamento da vida útil do produto, além da redução do peso e consequente redução do custo de transporte e armazenamento. Porém, as desvantagens se relacionam ao fato deste processo 
não ser tão eficiente, devido a dependência das condições climáticas, alta taxa de radiação solar, baixa umidade relativa do ar e baixo índice de poluição, além da ocorrência de pragas e microrganismos (CELESTINO, 2010; CORNEJO; NOGUEIRA; WILBERG, 2021).

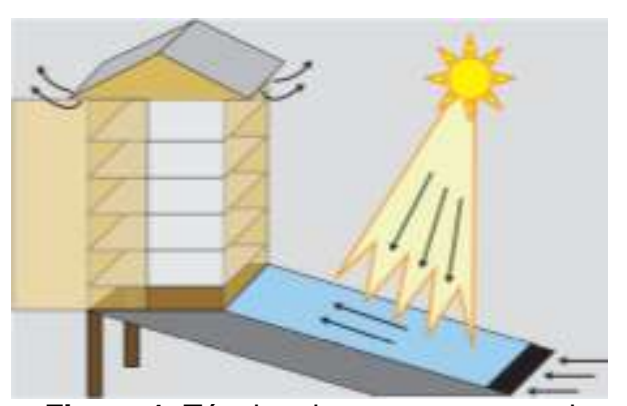

Figura 1. Técnica de secagem natural Fonte: Celestino (2010).

\section{Secagem em leito fixo}

Nos secadores de leito fixo, o produto fica estático durante a secagem e o ar aquecido é forçado a passar pela massa do produto. Essa técnica ainda pode ser utilizada na secagem em camada espessa ou em camada fina. Além disso, este método possui algumas vantagens, no entanto, assim como os demais também podem acarretar em uma perda de substâncias, como os compostos bioativos, que estão suscetíveis durante o processamento. A fim de diminuir os impactos desfavoráveis que a secagem pode provocar, muitos pesquisadores recorrem à aplicação de alguns métodos combinados com essa técnica, como os pré-tratamentos, para evitar o escurecimento enzimático, a perda de aromas e a perda da cor natural dos alimentos (RODRIGUES; MARFIL, 2020; SILVA; SOUZA; BARROZO, 2018; ULLMANN et al., 2014).

A Figura 2 apresenta um tipo de secador aplicado nesse método de secagem, porém, ressalta-se que podem haver diversidades de aparelhos experimentais para secagem em leito fixo.

Esta técnica de secagem é geralmente empregada em frutas por conta do seu baixo custo de implantação, por possuírem uma configuração simples, por não requerer um maior gasto de energia para movimentar todas as partes do leito e por minimizarem os danos mecânicos ao material. Além da sua versatilidade, pois podem ser utilizados com diferentes modelos experimentais.

Nesse contexto, a Tabela 2 apresenta diversos estudos que utilizaram a secagem em leito fixo para conservação de uma diversidade de frutas.

Considerando a maior retenção de compostos nutricionais, aliada a menor umidade final da fruta, a secagem por leito fixo mostrou-se mais eficaz para abacaxi, pistache e mamão formoso. No entanto, os resultados estão diretamente relacionados à espessura, velocidade e principalmente, às temperaturas utilizadas em cada estudo, bem como a fruta escolhida, levando em consideração que cada fruta possui umidades iniciais, bem como, textura e metabolismo distintos, o que influencia na retirada de umidade da fruta.

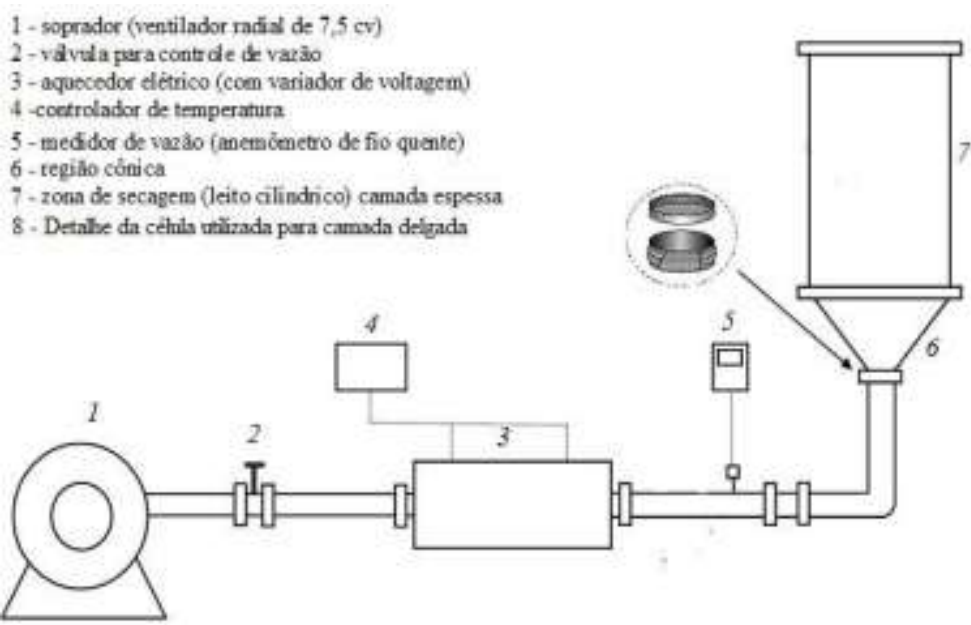

Figura 2. Modelo de secador de leito fixo

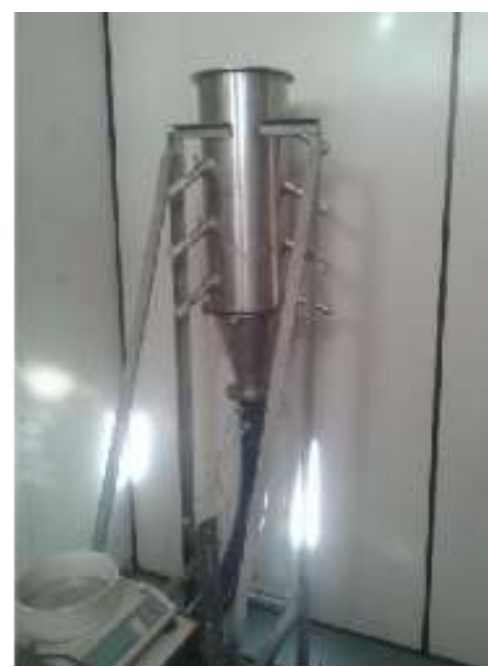
Fonte: Barrozo e Duarte (2017). 
Tabela 1. Secagem de frutas utilizando secagem natural Fruta

Maracujá amarelo

Depositadas em bandejas de aço inoxidável em

O teor de água inicial das amostras diminuiu para 1,23\% após 375 horas na faixa de temperatura ambiente que variou entre 25 e $38^{\circ} \mathrm{C}$.

Martins et al. (Passiflora edulis f. Flavicarpa) temperatura ambiente e cobertas com telas de náilon.

Manga

(Mangifera indica cv. Tommy atkins)

Tabela 2. Secagem de frutas em sistema de leito fixo

\begin{tabular}{|c|c|c|c|}
\hline Fruta & Parâmetros de estudo & Principais resultados & Ref. \\
\hline $\begin{array}{l}\text { Abacaxi } \\
\text { (Ananas } \\
\text { comosus) }\end{array}$ & $\begin{array}{l}\text { Temperatura de } 40^{\circ} \mathrm{C} \text {, velocidade do ar de } \\
0,45 \mathrm{~m} / \mathrm{s} \text {, espessura do abacaxi de } 0,5 \mathrm{~cm} \text { e } \\
\text { técnica combinada com pré-tratamento } \\
\text { osmótico (1 litro de água para } 400 \mathrm{~g} \text { de } \\
\text { sacarose). }\end{array}$ & $\begin{array}{l}\text { Com o pré-tratamento osmótico apresentou um teor de umidade menor }(18,07 \%) \text {, } \\
\text { em comparação as amostras sem pré-tratamento }(20,83 \%) ; \\
\text { Menor valor de dureza da fruta seca obtida sem pré-tratamento }(46,82 \%) \text {; } \\
\text { Maiores valores de elasticidade }(0,98 \%) \text { e coesividade }(0,84 \%) \text {, para as amostras } \\
\text { sem pré-tratamento. }\end{array}$ & $\begin{array}{l}\text { Rodrigues e Marfil } \\
\qquad(2020)\end{array}$ \\
\hline $\begin{array}{c}\text { Mamão } \\
\text { formosa } \\
\text { (Carica papaya } \\
\text { L.) }\end{array}$ & $\begin{array}{l}\text { Influência da espessura da amostra }(5,10 \text { e } \\
15 \mathrm{~mm}) \text { em razão da temperatura fixa }\left(63^{\circ} \mathrm{C}\right) \\
\text { e da velocidade do ar }(1,0 \mathrm{~m} / \mathrm{s})\end{array}$ & $\begin{array}{l}\text { As umidades finais obtidas foram de } 14,97,12,04 \text { e } 11,60 \% \text {, para as espessuras de } \\
\qquad 5,10 \text { e } 15 \mathrm{~mm} \text {, respectivamente; } \\
\text { O tempo de secagem para as espessuras de } 5,10 \text { e } 15 \mathrm{~mm} \text { foi de } 8,14 \text { e } 17 \mathrm{~h}, \\
\text { respectivamente. }\end{array}$ & $\begin{array}{l}\text { Lima, Peixoto, } \\
\text { Saraiva (2017) }\end{array}$ \\
\hline $\begin{array}{l}\text { Manga } \\
\text { (Mangifera } \\
\text { indica) }\end{array}$ & $\begin{array}{l}\text { Temperatura de } 60^{\circ} \mathrm{C} \text { e velocidade do ar de } \\
2 \mathrm{~m} / \mathrm{s} \text {, com e sem pré-tratamento, em } \\
\text { proporção de peso entre o meio líquido e a } \\
\text { frutas de } 4: 1 ; \\
\text { Utilizando a técnica de duplo estágio (D3S) } \\
\text { como pré-tratamento, ocorreu a remoção } \\
\text { parcial e a incorporação de açúcares. }\end{array}$ & $\begin{array}{l}\text { Amostras pré-tratadas secas apresentaram tempos de secagem mais rápidos, sendo } \\
\qquad 84 \mathrm{~min}(\mathrm{D} 3 \mathrm{~S} \text { 1) e } 77 \mathrm{~min} \text { (D3S 2); } \\
\text { Amostras sem pré-tratamento obteve menor degradação de compostos fenólicos e } \\
\text { carotenoides: } 2,03 \mathrm{mg} \mathrm{AGE/g} \mathrm{DM} \mathrm{e} \mathrm{10,35} \mathrm{mg/g} \mathrm{DM,} \mathrm{respectivamente.}\end{array}$ & $\begin{array}{l}\text { Medeiros et al. } \\
\qquad(2016)\end{array}$ \\
\hline
\end{tabular}


Maiores degradações de antocianinas ocorreram na temperatura de $50{ }^{\circ} \mathrm{C}$, sendo $59,19 \%, 42,29 \%$ e $76,47 \%$, nas vazões de $0,120,0,323$ e $0,340 \mathrm{~m}^{3} / \mathrm{s}$;

Açaí Temperaturas $\left(50,60\right.$ e $\left.70^{\circ} \mathrm{C}\right)$, e vazões de $\left(0,120,0,323\right.$ e $\left.0,340 \mathrm{~m}^{3} / \mathrm{s}\right)$

Secador de leito fixo não foi capaz de reduzir, para níveis adequados, o teor de umidade (umidade final de $49 \%$ ) e ainda reduziu para cerca de $50 \%$ o teor inicial de antocianinas $(47,19 \mathrm{mg})$.

\begin{tabular}{|c|c|c|c|}
\hline $\begin{array}{l}\text { Acerola } \\
\text { (Malpighia } \\
\text { emarginata } \\
\text { D.C.) }\end{array}$ & $\begin{array}{l}\text { Temperaturas }\left(31,7 \text { e } 88,3^{\circ} \mathrm{C}\right) \text {, velocidade do } \\
\text { ar de }(0,12 \text { e } 0,68 \mathrm{~m} / \mathrm{s}) \text { e o tempo de } \\
\text { secagem }(159,3 \text { e } 300,7 \mathrm{~min})\end{array}$ & $\begin{array}{l}\text { Maior teor de compostos fenólicos }(2845,93 \mathrm{mg} \text { ácido gálico/100g) e flavonoides } \\
\text { totais }(3097,21 \mu \mathrm{g} \text { rutina/ } 100 \mathrm{~g}) \text {, obtido à } 60^{\circ} \mathrm{C}, 0,4 \mathrm{~m} / \mathrm{s} \text { e } 159,3 \mathrm{~min} \text {. }\end{array}$ & $\begin{array}{l}\text { Ullmann et al. } \\
\qquad(2014)\end{array}$ \\
\hline $\begin{array}{l}\text { Abacaxi } \\
\text { (Ananas } \\
\text { comosus) }\end{array}$ & $\begin{array}{l}\text { Temperaturas }\left(46 \text { e } 60{ }^{\circ} \mathrm{C}\right) \\
\text { e velocidade do } \operatorname{ar}(1,0 \text { e } 1,5 \\
\mathrm{m} / \mathrm{s})\end{array}$ & $\begin{array}{l}\text { ácido ascórbico }(84,27 \mathrm{mg} / 100 \mathrm{~g}) \text { e de compostos fenólicos }(13,796 \mathrm{mg} \text { de ácido } \\
\text { como o menor teor de umidade final }(1,42 \%) \text {, foram obtidos a } 60^{\circ} \mathrm{C} \text { com velocidade } \\
\text { de } 1,5 \mathrm{~m} / \mathrm{s} .\end{array}$ & Silva et al. (2013) \\
\hline
\end{tabular}

$\begin{array}{cc} & \\ & \\ \text { Pistache Siirt } & \text { Temperatura }(60,80 \mathrm{e} \\ \text { (SSPs) } & \left.100^{\circ} \mathrm{C}\right) \text { e velocidade do ar } \\ & (0,065,0,1 \text { e } 0,13 \mathrm{~m} / \mathrm{s}) .\end{array}$

O menor teor de umidade $(1,57 \%)$ foi obtido na temperatura de $100^{\circ} \mathrm{C}$ nas velocidades $0,1 \mathrm{~m} / \mathrm{s}$, em tempo de secagem de 420 min;

(SSPs)

O maior teor de umidade $(33,21 \%)$ foi obtido na temperatura de $100^{\circ} \mathrm{C}$, nas velocidades $0,13 \mathrm{~m} / \mathrm{s}$, no entanto o estudo foi finalizado em apenas $20 \mathrm{~min}$, caso contrário, o maior teor de umidade $(14,67 \%)$ seria na temperatura de $60^{\circ} \mathrm{C}$, em $0,065 \mathrm{~m} / \mathrm{s}$ e $400 \mathrm{~min}$.
Balbay, Şahin,

Karabatak (2011) 


\section{Secagem em camada de espuma}

A secagem em camada de espuma é uma técnica em que alimentos líquidos ou semilíquidos são processados formando uma espuma, com o uso de emulsificantes, e depois transformados em pó através da secagem. É utilizada para alimentos sensíveis ao calor, por manter a qualidade dos produtos, o sabor e o valor nutricional. Além disso, oferece grandes possibilidades comerciais, como a aplicação do pó formado na indústria de alimentos na preparação de sopas, sorvetes e sucos, podendo ser facilmente reidratado (ARAÚJO et al., 2017).

As vantagens deste método são as menores temperaturas de desidratação (o que preserva as qualidades nutricionais do produto e o sabor) e o menor tempo de secagem devido à maior área superficial exposta ao ar, o que aumenta a velocidade de remoção de água. Com isso, é obtido um produto final poroso e de fácil reidratação, com menor custo operacional (MELO et al., 2013).

O fluxograma da Figura 3 exemplifica as etapas da secagem em camada de espuma, na qual é fundamental a escolha de um agente espumante adequado a cada tipo de alimento, a fim de proporcionar a formação de uma espuma estável durante a secagem. Neste review são apresentados alguns dos aditivos reportados em estudos recentes, dentre eles: albumina, albumina de ovo e Emustab.

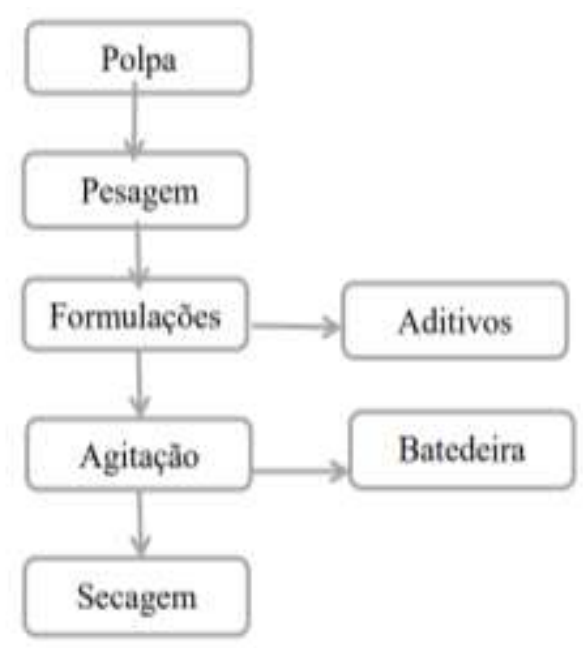

Figura 3. Fluxograma das etapas para a secagem em camada de espuma Fonte: Pê et al. (2016).

A Tabela 3 apresenta alguns estudos recentes que utilizaram a técnica de secagem em camada de espuma para obtenção de pó de diversas frutas. Os principais parâmetros analisados e resultados promissores também são descritos.

Com relação a técnica de camada de espuma como secagem de frutas apresentadas na Tabela 3, é possível verificar que as frutas: acerola, goiaba, cana-de-açúcar e mandacaru, obtiveram um menor tempo de secagem nas temperaturas mais elevadas (acima de $70^{\circ} \mathrm{C}$ ), no entanto, essa faixa de temperatura pode ocasionar perdas consideráveis das propriedades nutricionais, como vitaminas. Portanto, considerando os aspectos de tempo e menor degradação das propriedades físicoquímicas, as temperaturas de 50 e $60^{\circ} \mathrm{C}$, foram mais adequadas para secagem empregando essa técnica, sendo promissora para jambo, cagaita, pitanga, uvaia e mamão (Tabela 3).

\section{Secagem por atomização}

A secagem por atomização, nebulização ou spray drying é uma técnica que tem por finalidade transformar líquidos, como a polpa de algumas frutas em forma de pó, em um tempo de secagem relativamente curto. Este processo ocorre de modo que a atomização do líquido em um compartimento que recebe um fluxo de ar quente, onde ocorre a rápida evaporação da água e permite manter baixa a temperatura das partículas, permitindo assim a secagem de produtos sensíveis ao calor, sem afetar demasiadamente sua qualidade (SILVA; MORAIS; MACIEL, 2013).

Uma das vantagens deste método é que ele mantém as propriedades físico-químicas das frutas e em alguns casos, melhorar essas propriedades, o que permite um armazenamento prolongado e uma maior estabilidade e longevidade do produto, proporcionando ao consumidor o acesso ao produto durante todo o ano (SILVA; MORAIS; MACIEL, 2013).

O fluxograma da Figura 4 exemplifica as etapas para realização da secagem de frutas por atomização para obtenção do produto em pó. 
Tabela 3. Secagem de frutas empregando camada de espuma

Fruta Parâmetros de estudo

Temperaturas: 50, 60 e $70 \stackrel{\circ}{\circ}$;

Jambo Vermelho

(Syzygium

malaccense)

Agentes emulsificantes: Emustab nas proporções de $4,4,5$ e $5 \%(\mathrm{~m} / \mathrm{m})$;

Tempo de agitação: $8 \mathrm{~min}$.
Principais resultados

Ref.

Cinéticas de 435, 345 e $270 \mathrm{~min}$, para as temperaturas de 50, 60 e $70 \stackrel{\circ}{ } \mathrm{C}$, respectivamente;

A maior estabilidade das espumas foi obtida a partir de $4,5 \%(\mathrm{~m} / \mathrm{m})$ de emustab;

Rigueto et

al. (2020)

A temperatura de $50 \stackrel{\circ}{ } \mathrm{C}$ foi considerada a mais adequada, devido à maior retenção de vitamina $\mathrm{C}$ $(108,16 \mathrm{mg})$.
Temperaturas: $40,50,60$ e $70 \stackrel{\circ}{ } \mathrm{C}$;

Cagaita Agentes espumantes: Emustab, Super liga neutra

(Eugenia dysenterica DC) e Albumina nas proporções de 2, 4, 6, 8 e 10\% $(\mathrm{m} / \mathrm{m})$;
A maior atividade antioxidante $(60,44 \%)$ foi encontrada na temperatura de $60^{\circ} \mathrm{C}$, e o maior teor de vitamina $\mathrm{C}(166,14 \mathrm{mg} 100 \mathrm{~g}-1)$ em $50^{\circ} \mathrm{C}$

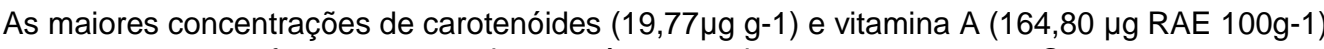
foram encontradas no pó preparado por secagem a $70^{\circ} \mathrm{C}$
Cavalcant

e et al.

(2020)

Tempo de agitação: 20 min.

A proporção de $8 \%$ de albumina identificou-se como o melhor agente formador de espuma.

Temperaturas: 60 e $70^{\circ} \mathrm{C}$;

Pitanga Agente espumante: Emustab na proporção de 5\%

(Eugenia uniflora) $(\mathrm{m} / \mathrm{m})$;

Maior teor de antocianina: $6,24 \mathrm{mg} / 100 \mathrm{~g}$, em $60^{\circ} \mathrm{C}$;

Maior teor de compostos fenólicos: $684,9 \mathrm{mg}$ de ácido gálico/100 g, em 70ํㅜ;

Geraldi et

O menor teor de umidade: $13,46 \%$ em $70 \stackrel{\circ}{\circ}$;

Tempo de agitação: 8 min

\begin{tabular}{|c|c|c|c|}
\hline $\begin{array}{c}\text { Morango } \\
\text { (Fragaria sp.) }\end{array}$ & $\begin{array}{l}\text { Temperaturas: } 55,60,65,70 \text { e } 75^{\circ} \mathrm{C} ; \\
\text { Agente espumante: albumina na proporção de } 1 \% \\
(\mathrm{~m} / \mathrm{m}) ;\end{array}$ & $\begin{array}{l}\text { A temperatura de secagem de } 65^{\circ} \mathrm{C} \text { causou a menor degradação das antocianinas (48\%), e a } \\
\text { temperatura de } 70^{\circ} \mathrm{C} \text { causou a maior degradação }(57,9 \%) ; \\
\text { O tempo de secagem foi maior para a temperatura de } 55^{\circ} \mathrm{C}(4 \mathrm{~h}) \text { e menor para a temperatura de } \\
\qquad 75^{\circ} \mathrm{C}(1,5 \mathrm{~h}) .\end{array}$ & $\begin{array}{l}\text { Vimercati } \\
\text { et al. } \\
\text { (2019) }\end{array}$ \\
\hline $\begin{array}{l}\text { Uvaia } \\
\text { (Eugenia } \\
\text { pyriformis) }\end{array}$ & $\begin{array}{l}\text { Temperaturas: } 50,60,70 \text { e } 80^{\circ} \mathrm{C} ; \\
\begin{array}{l}\text { Agentes emulsificantes: Emustab } \\
\text { nas proporções de } 4,4,5 \text { e } 5 \% \\
(\mathrm{~m} / \mathrm{m}) ;\end{array} \\
\text { Tempo de agitação: } 8 \text { min. }\end{array}$ & $\begin{array}{l}\text { Cinéticas de } 435 \text { e } 150 \text { min, para as temperaturas de } 50 \text { e } 80 \stackrel{\circ}{ } \mathrm{C} \text {, respectivamente; } \\
\text { A maior estabilidade das espumas foi obtida a partir de } 4,5 \%(\mathrm{~m} / \mathrm{m}) \text { de emustab; } \\
\text { a de } 50^{\circ} \mathrm{C} \text { foi considerada a mais adequada, devido à maior retenção de vitamina } \mathrm{C}(289,43 \mathrm{mg}) \text {. }\end{array}$ & $\begin{array}{l}\text { Rigueto et } \\
\text { al. (2018) }\end{array}$ \\
\hline
\end{tabular}

Continuação... 
Acerola $\quad$ Agentes espumantes: Emustab (Malpighia emarginata) $(3 \%)+$ Super Liga Neutra $(2 \%)$ $(\mathrm{m} / \mathrm{m})$;
Espumas secas a 60,70 e $80^{\circ} \mathrm{C}$ tiveram perdas de $0,330,0,311$ e $0,276 \%$ de água, com o tempo de secagem iguais a 5, 3 e 3 h respectivamente.
Gomes et

al. (2017)

\section{Espessura: $6 \mathrm{~mm}$.}

\begin{tabular}{|c|c|c|c|}
\hline $\begin{array}{l}\text { Goiaba } \\
\text { (Psidium guajava } \\
\text { L.) }\end{array}$ & $\begin{array}{l}\text { Temperaturas: } 75 \text { e } 85 \stackrel{\circ}{ } \text {; } \\
\text { Agente espumante: albumina nas } \\
\text { proporções de } 4 \text { e } 8 \%(\mathrm{~m} / \mathrm{m})\end{array}$ & $\begin{array}{l}\text { Utilizando a albumina a } 8 \% \text { obteve os melhores tempo de secagem, sendo } 99,70 \text { e } 68,93 \text { min., em } 75 \text { e } 85^{\circ} \mathrm{C} \\
\text { respectivamente, ambas até a razão de umidade de } 0,49 ; \\
\text { Utilizando a albumina a } 4 \% \text { obteve os maiores tempos de secagem, sendo } 107,66 \text { e } 88,30 \text { min. em } 75 \text { e } 85^{\circ} \mathrm{C} \text {, } \\
\text { respectivamente. }\end{array}$ & $\begin{array}{l}\text { Maciel et } \\
\text { al. (2016) }\end{array}$ \\
\hline $\begin{array}{l}\text { Caqui } \\
\text { (Diospyros kaki, } \\
\text { Linn) }\end{array}$ & $\begin{array}{l}\text { Temperatura: } 70 \stackrel{\circ}{ } \mathrm{C} ; \\
\text { Agentes espumantes: } \\
\text { Emulsificante, Liga neutra } \\
\text { Emulsificante + Liga neutra; } \\
\text { Tempo de agitação: } 5 \text { min. }\end{array}$ & $\begin{array}{l}\text { Tempo de equilíbrio de secagem foi de } 120 \mathrm{~min} \text {, para as três formulações de agentes testados; } \\
\qquad \text { O uso apenas do emulsificante favoreceu a maior redução no teor de água }(\approx 0,1) \text {. }\end{array}$ & $\begin{array}{c}\text { Pê et al. } \\
(2016)\end{array}$ \\
\hline $\begin{array}{l}\text { Cana de açúcar } \\
\text { (Saccarum } \\
\text { officinarum) }\end{array}$ & $\begin{array}{l}\text { Temperaturas: } 50,60 \text { e } 70 \text { ㅇ; } \\
\text { Agentes espumantes: combinação } \\
\text { de Emustab }(2,1 \%) \text {, Super Liga } \\
\text { Neutra }(0,70 \%) \text { e Carbonato de } \\
\text { Cálcio }(0,35 \%)(\mathrm{m} / \mathrm{m}) ; \\
\text { Tempo de agitação: } 5 \mathrm{~min} .\end{array}$ & $\begin{array}{l}\text { Menor tempo de secagem (180min) obtido a } 70^{\circ} \mathrm{C} \text {; } \\
\text { O produto desidratado apresentou umidade média de } 3,23 \% \text { e atividade de água média de } 0,360 \text {, utilizando a } \\
\text { temperatura de } 70^{\circ} \mathrm{C} \text {; }\end{array}$ & $\begin{array}{l}\text { Marques } \\
\text { et al. } \\
(2016)\end{array}$ \\
\hline $\begin{array}{l}\text { Abacaxi pérola, } \\
\text { acerola e } \\
\text { carambola }\end{array}$ & $\begin{array}{l}\text { Temperaturas: } 50,60 \text { e } 70^{\circ} \mathrm{C} \text {; } \\
\text { Agente espumante: Emustab em } \\
\text { proporções de } 4 \% \text {; } \\
\text { Tempo de agitação: } 10 \mathrm{~min} ; \\
\text { Espessura: } 5 \mathrm{~mm} \text {. }\end{array}$ & $\begin{array}{l}\text { O maior teor de ácido ascórbico no abacaxi, acerola e carambola, foi respectivamente: } 108,86,1369,02 \text { e } 37,68 \\
\qquad \mathrm{mg} / 100 \mathrm{~g} \text {, ambas em } 70^{\circ} \mathrm{C} ; \\
\text { Nas temperaturas mais elevadas }\left(70 \text { e } 60^{\circ} \mathrm{C}\right) \text {, as massas das espumas começaram a ficar constantes nos } \\
\text { tempos entre } 250 \text { e } 350 \text { minutos. }\end{array}$ & $\begin{array}{l}\text { Leal et al. } \\
\text { (2016) }\end{array}$ \\
\hline
\end{tabular}


Temperaturas: 70,80 e $90^{\circ} \mathrm{C}$;

Mandacaru (Cereus jamacaru P.)

Agentes espumantes: albumina $e$ Super Liga Neutra, à $2 \%(\mathrm{~m} / \mathrm{m})$;

Tempo de agitação: $5 \mathrm{~min}$;

Espessuras: 0,$5 ; 1,0$ e $1,5 \mathrm{~cm}$.
Menor tempo de secagem: 90 min., em $90^{\circ} \mathrm{C}$, com espessura de $0,5 \mathrm{~cm}$;

Maior tempo de secagem: $5 \mathrm{~h}$ e $30 \mathrm{~min}$., em $70^{\circ} \mathrm{C}$, com espessura de $1,5 \mathrm{~cm}$;

Melo et

Os melhores tempos de secagem com relação a espessuras foram obtidos pela temperatura de $90{ }^{\circ} \mathrm{C}$, sendo 1 al. (2013)

\section{Temperaturas: 60,65 e $70^{\circ} \mathrm{C}$;}

Agentes espumantes: albumina de ovo, nas concentrações de 5,10 15 e $20 \%(\mathrm{~m} / \mathrm{m})$;

Mamão

(Carica papaya L) Tempo de agitação: 5, 10, 15 e 20 $\min$;

Espessuras: 2, 4, 6 e $8 \mathrm{~mm}$.
Tempo de secagem da espessura da espuma, utilizando a temperatura de $60^{\circ} \mathrm{C}$, em um teor de umidade de $4,5 \%$ foi de $2,3,4$ e $5 \mathrm{~h}$, para espumas de $2,4,6$ e $8 \mathrm{~mm}$ de espessura;

As condições de $60^{\circ} \mathrm{C}$ foram consideradas adequadas, assim como a albumina do ovo a $15 \%$, tempo de agitação de 15 min e a espessura de $2 \mathrm{~mm}$, ambas em função da maior retenção de ácido ascórbico

$(140,42 \mathrm{mg}), \beta$-caroteno $(4,00 \mathrm{mg})$ e açúcares totais $(36,78 \mathrm{~g})$.

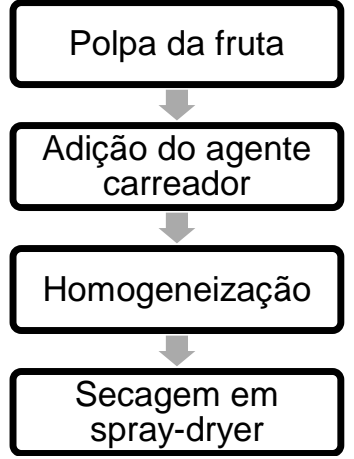

Figura 4. Fluxograma das etapas de secagem de frutas por atomização

Fonte: Adaptado de Ferreira et al. (2014). 
$\mathrm{Na}$ Tabela 4, observa-se que a secagem por atomização foi promissora para diversas frutas, entretanto, para a polpa de abacaxi com hortelã foi possível obter o pó até mesmo sem a adição do agente carreador, e portanto, Braga et al. (2020) relatam que o hortelã pode apresentar propriedades semelhantes à dos carreadores.

Ferreira et al. (2014) ressaltam que o uso dos agentes carreadores neste tipo de secagem em polpa de frutas é indispensável, já que as frutas contêm alto teor de açúcares, sendo favorável à caramelização, o que inviabilizaria o processo.

\section{Secagem em forno micro-ondas}

A secagem em forno micro-ondas (FMO) é um método que vem sendo bastante utilizado em diversas pesquisas que apontam resultados promissores, por proporcionar vantagens em comparação com a secagem por calor convencional, incluindo uma desidratação com redução no tempo e teor de água final do produto após secagem. Destacam-se também, a economia de energia, controle de processo preciso, além de oferecer produtos com boas características, e ser um método relativamente barato. No entanto, vale ressaltar que o efeito do aquecimento com relação aos nutrientes depende muito da espessura utilizada e da qualidade do tecido da fruta (ÖZCAN et al, 2019; AL JUHAIMI et al., 2016).

A secagem em FMO também pode ser combinada com outras técnicas de secagem, como secagem por ar quente (VARGAS et al., 2016), secagem a vácuo (BRUIJN et al., 2015; WOJDYŁO et al., 2013) e liofilização (IZLI; IZLI; TASKIN, 2017). Esse procedimento pode melhorar ainda mais a eficiência e a qualidade dos produtos secos (LOKHANDE; RANVEER; SAHOO, 2017).

$\mathrm{Na}$ Tabela 5 são apresentados estudos que objetivaram a secagem de frutas por FMO.

A partir da análise feita na Tabela 5 , é possível inferir que a secagem por FMO foi mais promissora para banana utilizando pré-tratamento osmótico, tomate e maçãs, considerando a obtenção do teor de umidade final abaixo de 10\%. Já do ponto de vista físico-químico, verifica-se que o kiwi e o pepino foram as frutas mais promissoras para esse método de secagem, uma vez que apresentaram 0 maior teor de compostos antioxidantes e o maior conteúdo de compostos fenólicos, respectivamente.

\section{Caracterização físico-química}

A análise físico-química das frutas in natura e secas, é realizada para a verificação da influência das técnicas de secagem nos parâmetros avaliados, de forma que seja possível estabelecer comparações com a matéria-prima sem modificações, tendo em vista que a desidratação da fruta utilizando aplicação de calor 'pode ocasionar a concentração ou perda de determinados compostos. Além disso, a partir dessas análises, podem ser obtidas informações acerca da qualidade, valor nutricional, rendimento e prazo de validade (NUNES et al., 2017; AUGUSTA et al., 2010).

A Figura 5 apresenta as principais análises físico-químicas realizadas nos estudos que foram apresentados anteriormente sobre secagem de frutas.

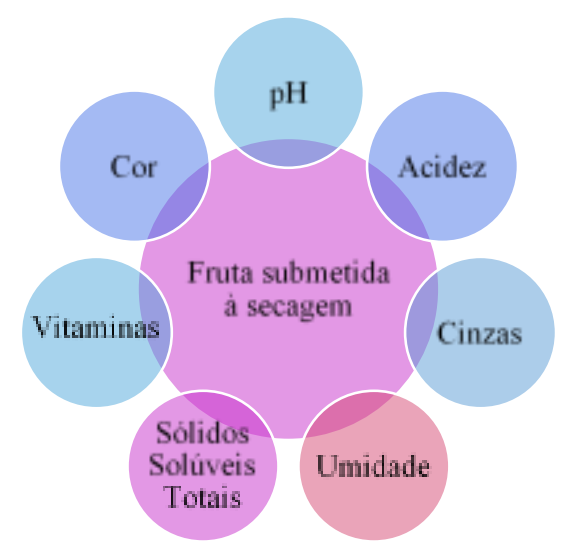

Figura 5. Principais análises físico-químicas realizadas em frutas submetidas a secagem

Identificar os compostos presentes nos produtos analisados é de extrema importância para análise de qualidade dos produtos, a seguir estão apresentadas as principais análises físico-químicas realizadas em frutas submetidas à secagem.

\section{Umidade}

A umidade é monitorada durante os experimentos cinéticos, tendo em mente que uma maior disponibilidade de água pode favorecer desenvolvimento microbiano no produto, diminuindo sua vida de prateleira. Desta forma, os resultados de teor de umidade ajudam a predizer se o método de secagem é eficaz (GERALDI et al., 2020).

De acordo com a legislação estabelecida pela Agência Nacional de Vigilância Sanitária (ANVISA), os produtos desidratados em forma de farinha de origem vegetal devem possuir um teor de umidade inferior a 15\% (m/m) (ANVISA, 2019).

\section{Cinzas}

A análise de cinzas é realizada para prever a quantidade de substâncias minerais presentes no material após sua queima, como por exemplo, ferro, fósforo, sódio, potássio e magnésio (RODRIGUES; FERREIRA; BARROS, 2014). Na caracterização desse composto em frutas secas pela técnica de camada de espuma, alguns pesquisadores observaram que a adição de emulsificantes para obtenção de uma espuma estável ocasiona um aumento significativo no teor de cinzas do produto final (GERALDI et al., 2020; RIGUETO et al., 2018).

De acordo com Rodrigues, Ferreira e Barros (2014) o teor de cinzas máximo para produtos de farinhas e farelos de origem vegetal estabelecido pela ANVISA é de $3 \%$, portanto, a análise desse parâmetro deve estar de acordo com o previsto pela legislação, tornando sua verificação importante. 
Santana e Silva et al. Técnicas de secagem de frutas: uma revisão

Tabela 4. Secagem de frutas por atomização

Fruta Metodologia do estudo

Temperatura: $105^{\circ} \mathrm{C}$

Abacaxi Pérola

(Ananas comosus

L.) e Hortelã

(Mentha spicata L.)

Agente carreador: Maltodextrina em três proporções 0, 3 e 10\% $(\mathrm{m} / \mathrm{m})$;

Secador: Spray dryer (LM MSD 1.0, LabMaq, Brasil) com ponta pulverizadora de $1,2 \mathrm{~mm}$ de diâmetro.
Principais resultados

Ref.

Foi possível obter o pó do suco de abacaxi com hortelã mesmo sem o uso de carreadores;

Com 0 aumento na concentração de maltodextrina obteve-se maior rendimento dos pós, houve redução da umidade, da atividade de água e da higroscopicidade.

Temperatura: 100 e $120^{\circ} \mathrm{C}$;

\begin{abstract}
Abacaxi Peróla (Ananas comosus)

Agente carreador: Maltodextrina nas proporções de 5, 10, 15 e $20 \%(\mathrm{~m} / \mathrm{m})$
\end{abstract}

Secador: Spray dryer (LM MSD 1.0, LabMaq, Brasil) com ponta pulverizadora de $1,2 \mathrm{~mm}$ de diâmetro.

Cajá-manga

(Spondias dulcis

Parkinson)

Temperaturas: 100,120 e $140^{\circ} \mathrm{C}$;

Agente carreador: Maltodextrina nas proporções de 5, 15 e 25\% $(\mathrm{m} / \mathrm{m})$;

Secador: Mini Spray dryer LM (LM MSD 1.0, LabMaq, Brasil), com ponta pulverizadora de $1,2 \mathrm{~mm}$ de diâmetro.
A temperatura de $100^{\circ} \mathrm{C}$ e concentração de $10 \%(\mathrm{~m} / \mathrm{m})$ de maltodextrina, foram as condições que propiciaram os melhores resultados para a acidez titulável $(0,88)$ e luminosidade $(21,60)$

Freitas et

al. $(2019)$
A temperatura de $100^{\circ} \mathrm{C}$ e concentração de $25 \%(\mathrm{~m} / \mathrm{m})$ de maltodextrina, causaram maior rendimento $(11,8 \%)$ de pó;

Rimoli et

al. (2019)

Porém, a temperatura de $140^{\circ} \mathrm{C}$ e concentração de $25 \%(\mathrm{~m} / \mathrm{m})$ de maltodextrina resultaram na coloração e sabor do produto mais aceito pelo consumidor.
Temperaturas: $148,154,169,184$ e $190^{\circ} \mathrm{C}$;

Graviola (Annona muricata L.)

Agente carreador: Maltodextrina nas proporções de 10, 12, 17, 22 e $24 \%(\mathrm{~m} / \mathrm{m})$;

Secador: Spray dryer (LM MSD 1.0, LabMaq, Brasil) com ponta pulverizadora de $1,2 \mathrm{~mm}$ de diâmetro.

\section{Temperatura: $120^{\circ} \mathrm{C}$;}

Seriguela (Spondias purpurea

L.)
Agentes carreadores: goma arábica, fécula de mandioca e maltodextrina, ambos na proporção de $10 \%(\mathrm{~m} / \mathrm{m})$;
As condições de secagem a $169^{\circ} \mathrm{C}$ com adição de $17 \%(\mathrm{~m} / \mathrm{m})$ de maltodextrina como agente carreador, propiciou maior rendimento dos pós com características físico-químicas e higroscópicas consideradas boas para pós alimentícios, com o teor de umidade de 1,3\% e atividade de água de 0,1.

A formulação de polpa de seriguela com a goma arábica apresentou os menores valores de umidade $(4,84 \%)$, grau de caking $(35,68 \%)$ e

higroscopicidade $(8,36 \%)$ quando comparado às demais formulações, indicando que esse produto tem melhor qualidade e tempo de vida útil mais prolongado.
Cavalcant

e et al.

(2017)

Secador: Mini Spray dryer LM (LM MSD 1.0, LabMaq, Brasil), com ponta pulverizadora de 1,2 mm de diâmetro. 
Temperatura: $120^{\circ} \mathrm{C}$;

Goiaba (Psidium Agente carreador: Maltodextrina (10\%) e água destilada (50\%) guajava L.) $(\mathrm{m} / \mathrm{m})$

Secador: Mini Spray dryer LM (LM MSD 1.0, LabMaq, Brasil), com ponta pulverizadora de $1,2 \mathrm{~mm}$ de diâmetro.
O pó de goiaba obtido perdeu em média $93,58 \%$ de água em relação à polpa integral;

o pó de goiaba apresentou teor médio de sólidos solúveis (93,00 ํㅏix) e açúcares totais $(34,64$ (g 100g-1) e redutores $(20,25 \mathrm{~g} 100 \mathrm{~g}-1)$,

Santos et

al. (2014)

significativamente, superior ao observado para polpa integral de goiaba $(8,43$ BBix, 2,84 e 2,79 g 100g-1, respectivamente).

\section{Temperaturas: 110 e $170 \stackrel{\circ}{\mathrm{C}}$}

Ciriguela (Spondias purpurea L.)

\section{Agentes carreadores: maltodextrina com dextrose equivalente}

10 , nas proporções de 14 e $26 \%(\mathrm{~m} / \mathrm{m})$, respectivamente;

Secador: Mini Spray dryer LM (LM MSD 1.0, LabMaq, Brasil), com ponta pulverizadora de $1,2 \mathrm{~mm}$ de diâmetro.
O ensaio 5 ( $110^{\circ} \mathrm{C}$ e $26 \%$ de agente carreador) apresentou as melhores condições de secagem, pois obteve um teor mais elevado de carotenoides totais $(6,13 \mu \mathrm{g} / 100 \mathrm{~g})$, baixo teor de atividade de água $(0,11$,

$$
(15,00) \text {. }
$$

Silva

Morais

Maciel

(2013)

\section{Temperaturas: 90 e $180 \stackrel{\circ}{\circ}$;}

Morango (Fragaria vesca L. cv. Oso Grande)

\section{Agentes carreadores: maltodextrina, goma arábica e amido} modificado com anidrido n-octanil succínico, ambos na proporção de $50 \%(\mathrm{~m} / \mathrm{m})$

Secador: Mini spray dryer (B-190, Buchi, Suíça).
A utilização dos quatro diferentes agentes carreadores resultou em pós com baixa umidade (2,27 - Maltodextrina 5DE; 1,85 - Maltodextrina 10DE; 2,45 Goma Arábica e 1,73 - Capsul);

A polpa de morango desidratada com goma arábica apresentou o maior teor de antocianinas $(90,42 \mathrm{mg} / 100 \mathrm{~g})$ e, consequentemente, maior valor de atividade antioxidante $(57,73 \mathrm{mg} / 100 \mathrm{~g})$

\section{Temperaturas: 160 e $180^{\circ} \mathrm{C}$}

Amora preta

(Morus alba L.)
Agente carreador: maltodextrina nas proporções de 5, 15 e 25\% $(\mathrm{m} / \mathrm{m})$
O aumento da temperatura do ar de secagem resultou em pós menos úmidos e com menor atividade de água, porém mais higroscópicos. Exemplo: amostra com $5 \%$ de maltodextrina, seca a $180^{\circ} \mathrm{C}$ que resultou em umidade de $1,23 \%$, atividade de água 0,260 e higroscopicidade $(29,51 \mathrm{~g} / 100 \mathrm{~g})$.
Ferrari, Ribeiro Aguirre (2012)

Secador: Mini spray dryer (B-290, Buchi, Suíça). 
Tabela 5. Secagem de frutas empregada por forno micro-ondas

\begin{tabular}{|c|c|c|c|}
\hline Fruta estudada & Parâmetros de estudo & Principais resultados & Ref. \\
\hline $\begin{array}{l}\text { Acerola (Malpighia } \\
\text { emarginata D. C.) }\end{array}$ & $\begin{array}{l}\text { Potência: } 700 \mathrm{~W} \text {; } \\
\text { Tempo: } 14 \text { min. }\end{array}$ & $\begin{array}{c}\text { Reduziu o teor de água final, necessitando apenas de tempo de secagem de } 14 \mathrm{~min} \text { para } \\
\text { atingir o teor de água final de } 24 \% \text {. }\end{array}$ & $\begin{array}{l}\text { Sousa et al. } \\
\text { (2020) }\end{array}$ \\
\hline
\end{tabular}

Tempo: 14 min.

\begin{tabular}{|c|c|c|c|}
\hline $\begin{array}{l}\text { Banana nanica (Musa } \\
\text { acuminata 'Dwarf } \\
\text { Cavendish') }\end{array}$ & $\begin{array}{l}\text { Potência: } 800 W \\
\text { Tempo: } 15 \text { min; } \\
\text { Com e sem a desidratação osmótica da } \\
\text { banana, preparadas em três soluções } \\
\text { saturadas de água e açúcar, com } \\
\text { proporções de } 50 / 50,60 / 40 \text { e } 65 / 35 \text { de } \\
\text { açúcar/água. }\end{array}$ & $\begin{array}{l}\text { A secagem por micro-ondas foi satisfatória, visto que foi possível obter o teor de umidade: } \\
\qquad 29,38 \% \text { na banana sem o pré-tratamento; } \\
\text { Já as bananas desidratadas osmoticamente apresentaram um teor de umidade: } 32,33 \% \text {, } \\
\qquad 4,83 \% \text { e } 120 \% \text { respectivamente. }\end{array}$ & $\begin{array}{c}\text { Geromel e } \\
\text { Freitas }(2020)\end{array}$ \\
\hline $\begin{array}{l}\text { Kiwi (Actinidia } \\
\text { deliciosa) e pepino } \\
\text { (Solanum muricatum } \\
\text { Aiton) }\end{array}$ & $\begin{array}{l}\text { Potência: } 720 \text { W; } \\
\text { Tempo: } 3 \text { min. }\end{array}$ & $\begin{array}{l}\text { Obteve uma umidade final em forno micro-ondas do Kiwi e pepino, respectivamente: } 20,457 \\
\qquad \text { e } 21,681 \% \text {; } \\
\text { Melhoria de atividades antioxidantes (92.343 e } 90.618 \%) \text { e conteúdo fenólico total }(1117,319 \\
\text { e } 1812,793 \mathrm{mg} / 100 \mathrm{~g} \text { DW) de ambas as frutas, respectivamente para kiwi e pepino. }\end{array}$ & $\begin{array}{l}\text { Özcan et al. } \\
\quad(2019)\end{array}$ \\
\hline $\begin{array}{l}\text { Tomate } \\
\text { (S. lycopersicum L. cv } \\
\text { "Suzukoma") }\end{array}$ & $\begin{array}{l}\text { Micro-ondas e micro-ondas à vácuo; } \\
\text { Potência: } 200 \text { W. }\end{array}$ & $\begin{array}{l}\text { Menor tempo de secagem, sendo necessários para o micro-ondas a vácuo e forno de micro- } \\
\text { ondas: } 0,45 \text { e } 0,58 \mathrm{~h} \text { para reduzir o teor de umidade de } 16,6 \text { para menos de } 0,2(\mathrm{db}) \\
\text { Maior atividade antioxidante }(70,18 \%) \text { em micro-ondas a vácuo. }\end{array}$ & $\begin{array}{l}\text { Orikasa et al. } \\
(2018)\end{array}$ \\
\hline $\begin{array}{l}\text { Manga (Mangifera } \\
\text { indica L.). }\end{array}$ & $\begin{array}{l}\text { Potências: } 120 \text { e } 350 \mathrm{~W} \text {; } \\
\text { Espessura de } 3 \mathrm{~mm} \text {. }\end{array}$ & $\begin{array}{l}\text { Menor duração de secagem por micro-ondas de } 350 \mathrm{~W} \text { (14 min); } \\
\text { Maior valor de conteúdo fenólico total }(286,83 \mathrm{mg}) \text { obtido por micro-ondas a } 350 \mathrm{~W} \text {. }\end{array}$ & $\begin{array}{l}\text { Izli, İzli, Taskin } \\
\quad(2017)\end{array}$ \\
\hline $\begin{array}{l}\text { Uvas } \\
\text { (Vitis vinifea) }\end{array}$ & $\begin{array}{l}\text { Potências: } 350 \text { a } 1000 \text { W } \\
\text { Utilizou para as amostras de controle } \\
\text { diferentes pré-tratamentos: mistura de } \\
\text { solução de soda cáustica } 0,5 \% \text {, etiloleato } 1 \% \\
\text { e meta-bissulfito de potássio } 1 \% \text {. }\end{array}$ & $\begin{array}{l}\text { Menor tempo de secagem: } 20 \text { minutos, para remover } 65 \% \text { de umidade das uvas; } \\
\text { Maior retenção de ácido ascórbico(11,92mg) e razão de reidratação }(2,50 \%) \text { ocorreu em } \\
750 \mathrm{~W} ; \\
\text { A textura física das bagas tratadas com solução de soda cáustica a } 0,5 \% \text { (T-2), } \\
\text { apresentaram mais rachaduras na superfície. }\end{array}$ & $\begin{array}{l}\text { Lokhande, } \\
\text { Ranveer, Sahoo } \\
\text { (2017) }\end{array}$ \\
\hline
\end{tabular}




\section{Maçã (Golden, Granny Desidratação das quatro cultivares de maçã Smith, Pink Lady e Starking) secas em micro-ondas a 180 ou $54 \mathrm{~W}$; Fatias com espessuras de 3-4 mm.}

O menor teor de umidade: 7,84\% (Pink Lady), seco em um micro-ondas a 540 W;

Maiores teores de fenólicos totais e níveis de atividade antioxidante, respectivamente: 475,63mg (Starking) e 78,81\% (Granny Smith) em micro-ondas a 540W.
Al Juhaimi et al.

A maçã apresentou a maior taxa de secagem $(8,8 \mathrm{~g})$, já o abacaxi apresentou a menor taxa de secagem (15,9g), em comparação com os teores de umidade das demais frutas: Goiaba $(9,5 \mathrm{~g})$, Manga $(13,8 \mathrm{~g})$ e Banana $(12 \mathrm{~g})$;

Vargas et al.

O menor tempo de secagem foi obtido pela maçã (110min).
Maçã, goiaba, manga, micro-ondas;

Potência nominal máxima de 900W.

Reduziu o teor de umidade de morangos frescos de $90,4 \%$ para $29,3 \%$;

Morangos (Fragaria ananassa, cv. San Andreas)

Secagem por micro-ondas assistida a vácuo; Potência de $700 \mathrm{~W}$.

$$
\text { Houve redução das antocianinas }(0,51 \mathrm{mg}) \text {; }
$$

As amostras secas obtiveram uma boa pontuação de qualidade geral, ficando entre boa e média, para os atributos de cor, aparência geral, doçura, elasticidade e dureza.
Cerejas azedas (Prunus cerasus)
Secagem por micro-ondas a vácuo; Potência de $240 \mathrm{~W}, 360 \mathrm{~W}$ e $480 \mathrm{~W}$.
Maior teor de polifenóis: 7,587.33mg em 480W;

Menor teor de polifenóis: 6,195.35mg em 360W;

Wojdyło et al.

A secagem por micro-ondas resultou na maior retenção de antocianinas (70\% a $90 \%$ de retenção do extrato original). 


\section{Sólidos solúveis totais}

O teor de sólidos solúveis totais (SST) é o parâmetro que representa todos os sólidos dissolvidos na água, entre eles estão o conteúdo de açúcares (glicose, frutose e sacarose), sais, proteínas e ácidos orgânicos que possuem relação direta com o grau de doçura do produto, por isso o oBrix pode ser considerado, basicamente, como a percentagem de açúcar presente no líquido (LIMA; LIMA; GALVÃO, 2011).

Além disso, o SST auxilia durante análise de qualidade dos frutos in natura e as frutas que foram submetidas de secagem, pois os diferentes estágios de maturação da fruta interferem nos teores de SST, o que pode interferir diretamente no rendimento de produtos vegetais durante 0 processamento industrial, visto que elevados teores desses constituintes implicam em um menor teor de umidade do produto desidratado. Ademais, nos estudos reportados, verificou-se que na secagem por atomização, a adição de agentes carreadores como a maltodextrina é responsável pelo aumento do teor de sólidos solúveis totais (RIGUETO et al, 2018; CAVALCANTE et al., 2017; SANTOS et al., 2014; FERRARI; RIBEIRO; AGUIRRE, 2012).

\section{Vitaminas}

As vitaminas estão presentes em diversas frutas, sendo componentes indispensáveis para o funcionamento do organismo, trazendo benefícios à saúde do consumidor. A vitamina C, por exemplo, também conhecida como ácido ascórbico, é essencial para funções biológicas do sistema imunológico, prevenindo doenças cardíacas e câncer (MENDONÇA JR et al., 2010).

No entanto, durante o processo de secagem essas vitaminas das frutas podem ser volatilizadas, pois são termolábeis, ou seja, sensíveis à ação da temperatura de aquecimento e luminosidade. Logo, a análise físico-química para comparação da fruta in natura e seca desempenha um papel importante para a verificação de vitaminas volatilizadas durante a secagem, para que seja possível definir qual a melhor faixa de temperatura, a fim de reter a maior quantidade de vitaminas presentes na fruta (RIGUETO et al., 2018; MARSANASCO et al., 2011).

\section{Cor}

A cor é considerada um atributo de qualidade das frutas tanto in natura, quanto secas, já que grande parte dos consumidores utilizam desse aspecto visual como um fator de aceitação e de escolha para o seu consumo (SILVA et al., 2020). Entretanto, o processo de secagem por si só, depende exclusivamente da temperatura e da potência aplicada, e esses fatores tendem a levar a uma significativa redução na cor. Logo, utilizar temperaturas elevadas ou longos períodos de secagem, podem acarretar na degradação de pigmentos, tornando necessário a verificação desse parâmetro (LOKHANDE; RANVEER; SAHOO,
2018; IZLI; IZLI; TASKIN, 2017; MEDEIROS et al., 2016; WOJDYŁO et al., 2013).

Além disso, a mudança de cor pode estar diretamente ligada à reação não enzimática (reação de Mailard) e à enzimática, que ocorre por meio de reações catalisadas por uma enzima conhecida por polifenoloxidase (PPO). A reação de Maillard ocorre em alimentos que possuem elevados teores de açúcares redutores, os quais iniciam suas reações durante 0 aquecimento, 0 que dá origem as melanoidinas, que são os pigmentos marrons, originando frutas mais escuras (RODRIGUES; MARFIL, 2020; FRANCISQUINI et al., 2017; SHIBAO; BASTOS, 2011).

Ademais, a adição de agentes carreadores, como maltodextrina, também podem favorecer a perda dos pigmentos do produto (SILVA et al., 2020; FERRARI; RIBEIRO; AGUIRRE, 2012).

\section{pH e acidez}

$\mathrm{O} \mathrm{pH}$ é um indicador químico de concentrações de íons de hidrogênio em um meio, responsável pela característica ácida e por auxiliar na inibição de atividade enzimática e microbiana das frutas, proporcionando um aumento na vida de prateleira. $\mathrm{O} \mathrm{pH}$ das frutas depende de fatores, como o estado de preservação e a condição das matérias-primas utilizadas (RODRIGUES; GERALDI; LOSS, 2020; TELLES, 2012).

$\mathrm{O} \mathrm{pH}$ possui uma relação inversamente proporcional com a acidez, tendo em vista que na escala de $\mathrm{pH}$ os valores que são classificados como inferior a 7, indicam a presença de um meio ácido, já se às substâncias são classificadas como superiores a 7 , são considerados meios básicos ou alcalino, e caso for classificado como 7 é um meio neutro (CUNHA et al., 2016).

Logo, o teor de acidez durante a secagem de frutas, tende a se concentrar com a retirada de água do produto, além disso, o grau de maturação da fruta tem influência direta sobre esse parâmetro, pois quanto mais maduras estão, menor é o seu teor de acidez (VIEIRA et al., 2014; RODRIGUES; GERALDI; LOSS, 2020).

Além destes parâmetros, também podem ser analisados outros critérios como atividade de água, teor de antocianinas, teor de polifenóis, compostos fenólicos, atividade antioxidante, entre outros, os quais puderam ser observados nos experimentos citados anteriormente.

\section{Modelagem matemática}

Durante anos, os modelos desenvolvidos foram usados em cálculos que envolviam o projeto e construção de novos sistemas, otimização do processo e a descrição de todo 0 seu comportamento. A maioria dos estudos relacionados à secagem se referem ao resultado de diversas variáveis externas sobre o produto, como a temperatura, velocidade do ar, umidade relativa, entre outros. Portanto, os modelos matemáticos são utilizados para representar a cinética de secagem referente a estas condições, sendo que 
estes são fundamentais para as simulações matemáticas de secagem (GONELI et al., 2014; ONWUDE et al., 2016).

A Tabela 6 apresenta os principais modelos matemáticos utilizados para descrever 0 comportamento da cinética de secagem de produtos alimentícios, bem como suas respectivas equações.

Para o cálculo da razão de umidade $(R U)$, durante a secagem utiliza-se a seguinte expressão:

$$
R U=\frac{U-U e}{U i-U e}
$$

Onde: $\mathrm{U}=$ teor de água do produto (decimal, b.s.), $\mathrm{Ui}-$ teor de água inicial do produto (decimal, b.s.), Ue = teor de água de equilíbrio do produto (decimal b.s.).

Os modelos sem teóricos são baseados no modelo teórico da segunda lei da difusão de Fick ou da lei do resfriamento de Newton, sendo o último, uma versão simplificada do primeiro (ONWUDE et al., 2016).

De acordo com Onwude et al. (2016), o modelo Newton/Lewis (Equação 3), é considerado o modelo mais simples, devido à constante de modelo único, onde $\mathrm{k}$ é a constante de secagem, sendo este modelo reportado com bons ajustes à cinética de secagem de abacaxi (RODRIGUES; MARFIL, 2020).

O modelo de Page (Equação 12), é uma modificação empírica do modelo de Newton, em que os erros associados ao uso do antigo modelo são bastante minimizados pela adição de uma constante empírica adimensional (n), sendo amplamente reportado no ajuste de diversas frutas e produtos agrícolas. Nos estudos reportados nesse review, o modelo de Page ajustou-se bem à cinética de secagem da uvaia (RIGUETO et al., 2018), jambo vermelho (RIGUETO et al., 2020), morango (VIMERCATI et al., 2019), mamão (LIMA; PEIXOTO; SARAIVA, 2017), abacaxi, acerola e carambola (LEAL; GERALDI; KLASSEN, 2016).

No modelo Page modificado (Equação 13), Erbay e Icier (2010), relatam que existem 3 fórmulas que podem descrevê-lo, porém na Tabela 6 está representada a mais conhecida, descrita como modelo de Page Modificado, que apresenta 2 constantes.

Onwude et al. (2016), também relatam que o modelo de Henderson e Pabis (Equação 4) é o primeiro termo da solução geral da segunda lei de difusão de Fick, e é considerado um modelo simples, já que apresenta apenas 2 constantes, onde a representa a forma dos materiais usados (adimensional).

O modelo de Midilli e Kucuk (Equação 6), é uma modificação do modelo de Henderson e Pabis, com a adição de um t extra com um coeficiente. Esse modelo apresentou bons ajustes à cinética de secagem da uvaia (RIGUETO et al., 2018), jambo vermelho (RIGUETO et al., 2020) e açaí (SILVA; FARIA; COSTA, 2014).

Já o modelo Logarítmico (Equação 9), também é uma forma modificada do modelo de Henderson e Pabis, apenas com a adição de um termo empírico, o que o leva a ter 3 constantes.

Tabela 6. Modelos matemáticos comumente utilizados para descrever a secagem de produtos alimentícios

\begin{tabular}{|c|c|c|}
\hline Modelo & Equação & \\
\hline Difusão (Lei de Fick) & $R U=\frac{U-U e}{U i-U e}=\frac{8}{\pi^{2}} \sum_{n=0}^{\infty} \frac{1}{(2 n+1)^{2}} \exp \left[-(2 n+1)^{2} \pi^{2} D \frac{t}{4 L^{2}}\right]$ & (1) \\
\hline Aproximação da difusão & $R U=a \exp (-k t)+1-a \exp (-k b t)$ & $(2)$ \\
\hline Newton/Lewis & $R U=\exp (-k t)$ & (3) \\
\hline Henderson e Pabis & $R U=a \exp (-k t)$ & $(4)$ \\
\hline Henderson e Pabis modificado & $R U=a \exp (-k t)+b \exp \left(-k_{0} t\right)+c \exp \left(-k_{1} t\right)$ & $(5)$ \\
\hline Midilli e Kucuk & $R U=a \exp \left(-k t^{n}\right)+b t$ & (6) \\
\hline Dois Termos & $R U=a \exp \left(-k_{0} t\right)+b \exp \left(-k_{1} t\right)$ & $(7)$ \\
\hline Exponencial de Dois Termos & $R U=a \exp (-k t)+(1-a) \exp (-k a t)$ & (8) \\
\hline Logarítmico & $R U=a \exp (-k t)+c$ & $(9)$ \\
\hline Thompson & $t=a \ln (R U)+b[\ln (R U)]^{2}$ & $(10)$ \\
\hline Wang e Sing & $\mathrm{RU}=1+\mathrm{at}+\mathrm{bt}^{2}$ & $(11)$ \\
\hline Page & $R U=\exp \left(-k t^{n}\right)$ & (12) \\
\hline Page modificado & $R U=\exp \left[-\left(k t^{n}\right)\right]$ & $(13)$ \\
\hline
\end{tabular}




\section{Conclusão}

Este review abordou diferentes métodos de secagem aplicados às frutas, sendo eles: secagem natural, leito fixo, camada de espuma, atomização e por micro-ondas. Foram evidenciados os principais resultados promissores de cada estudo.

Além disso, as principais análises físico-químicas e os modelos matemáticos empregados na modelagem dos dados experimentais, também foram apresentados.

Com relação às perspectivas para trabalhos futuros, ressaltamos que o avanço de técnicas de conservação de frutas, que objetivem maior vida de prateleira, aliada à maior retenção de compostos de interesse nutricional, podem trazer benefícios relacionados à redução de perdas, maior saudabilidade e geração de renda. Portanto, a continuidade de estudos reportando as melhores condições operacionais em batelada é fundamental para aplicações em grandes volumes.

\section{Referências}

ALBUQUERQUE, T. G. et al. Nutritional and phytochemical composition of Annona cherimola Mill. fruits and by-products: Potential health benefits. Food Chemistry, v. 193, p. 187-195, 2016.

AL JUHAIMI, F. et al. Effects of oven and microwave drying on phenolic contents and antioxidant activities in four apple cultivars. Quality Assurance and Safety of Crops \& Foods, v. 8, n. 1, p. 51-55, 2016.

ANJOS, E. V.; SILVA, J. A. Cinética de secagem e modelagem matemática do fruto de buriti (Mauritia flexuosa). Blucher Chemical Engineering Proceedings, v. 1, n. 3, p. 1968-1973, 2015.

ARAÚJO, C. S. et al. Cinética de secagem de acerola em leito de espuma e ajuste de modelos matemáticos. Brazilian Journal of Food Technology, v. 20, p. 2016152, 2017.

ARAÚJO, K. T. A. et al. Caracterização físicoquímica de farinhas de frutas tropicais. Revista Brasileira de Agrotecnologia, v. 7, n. 2, p. 110-115, 2017.

ARAÚJO, W. D. et al. Modelagem matemática da secagem dos frutos de amendoim em camada delgada. Revista Ciência Agronômica, v. 48, n. 3, p. 448-457, 2017.

ANVISA. BRASIL. Agência Nacional de Vigilância Sanitária. Consulta Pública no 80. Diário Oficial da União - Brasília, DF, Brasil, 2019.

AUGUSTA, I. M. et al. Caracterização física e química da casca e polpa de jambo vermelho (Syzygium malaccensis,(L.) Merryl \& Perry). Food Science and Technology, v. 30, n. 4, p. 928-932, 2010.
BALBAY, A.; ŞAHIN, Ö.; KARABATAK, M. An investigation of drying process of shelled pistachios in a newly designed fixed bed dryer system by using artificial neural network. Drying Technology, v. 29, n. 14, p. 1685-1696, 2011.

BALBAY, A. et al. Modeling of drying process of bittim nuts (Pistacia terebinthus) in a fixed bed dryer system by using extreme learning machine. International Journal of Food Engineering, v. 8, n. 4, 2012.

BARBOSA, L. S. et al. Estudo da secagem de frutos tropicais do nordeste. Revista Verde, v. 9, n.1, p.186-190, 2014.

BARROZO, M. A. S.; DUARTE, C. R. Laboratório de Leito Fixo. Disponível em: http://www.ppgeq.feq.ufu.br/laboratorios-depesquisa/laboratorio-de-leito-fixo. Acesso em 29/04/2021.

BRAGA, V. et al. Production and characterization of pineapple-mint juice by spray drying. Powder Technology, v. 375, p. 409-419, 2020.

BRUIJN, J. et al. Effect of vacuum microwave drying on the quality and storage stability of strawberries. Journal of Food Processing and Preservation, v. 40, n. 5, p. 1104-1115, 2015.

CANGUSSU, L. B. Engenharia de Alimentos: Inovações promissoras. Belo Horizonte: Synapse Editora, 2020. Disponível em: https://www.editorasynapse.org/wp-

content/uploads/2020/11/Engenharia-de-AlimentosV0.pdf. Acesso em 03/05/2021.

CAVALCANTE, C. E. B. et al. Avaliação dos parâmetros de secagem da polpa de graviola em pó obtida por secagem em spray dryer. Brazilian Journal of Food Technology, v. 20, p. 2016015, 2017.

CAVALCANTE, M. D. et al. Quality of cagaita powder by foam layer drying method and different foamer agents. Engenharia Agrícola, v. 40, n. 3, p. 381-387, 2020.

CELESTinO, S. M. C. Princípios de secagem de alimentos. $1^{\text {o }}$ ed. Planaltina: Embrapa, 2010. Disponível em: https://ainfo.cnptia.embrapa.br/digital/bitstream/item/ 77765/1/doc-276.pdf. Acesso em 03/05/2021.

COELHO E. M.; AZEVEDO, L. C. Comparação entre técnicas de secagem para obtenção de farinha a partir da casca de manga cv. Tommy Atkins. In: Congresso Norte Nordeste de Pesquisa e Inovação, VII, 2012, Palmas. Anais eletrônicos. Palmas: Instituto Federal de Educação, Ciência e Tecnologia do Tocantins, 2012. Disponível em: https://propi.ifto.edu.br/ocs/index.php/connepi/vii/pa per/viewFile/705/2640. Acesso em: 03/05/2021. 
CORNEJO, F. E. P.; NOGUEIRA, R. I.; WILBERG, V. C. Secagem e desidratação. Disponível em: https://www.agencia.cnptia.embrapa.br/gestor/tecno logia_de_alimentos/arvore/CONT000fid5sgie02wyiv 80z4s473tokdiw5.html. Acesso em 05/05/2021.

CORRÊA, P. C. et al. Modelagem matemática e determinação das propriedades termodinâmicas do café (Coffea arabica L.) durante o processo de secagem. Revista Ceres, v. 57, n. 5, p. 595-601, 2010.

CUNHA, M. F. et al. Acidez, sua relação com pH e qualidade de geleias e doces em barra. Boletim técnico IFTM, n. 2, p. 14-19, 2016.

DUZZIONI, A. G. et al. Effect of drying kinetics on main bioactive compounds and antioxidant activity of acerola (Malpighia emarginata DC) residue. International journal of food science \& technology, v. 48, n. 5, p. 1041-1047, 2013.

ERBAY, Z.; ICIER, F. Uma revisão da secagem em camada fina de alimentos: teoria, modelagem e resultados experimentais. Critical Reviews in Food Science and Nutrition, v. 50, n. 5, p. 441- 464, 2010.

FARIA, R. Q. et al. Cinética de secagem de sementes de crambe. Revista Brasileira de Engenharia Agrícola e Ambiental, v.16, n.5, p. 573583, 2012.

FERRARI, C. C.; RIBEIRO, C. P.; AGUIRRE, J. M. Secagem por atomização de polpa de amora-preta usando maltodextrina como agente carreador. Brazilian Journal of food technology, v. 15, n. 2, p. 157-165, 2012.

FERREIRA, A. P. R. et al. Comportamento higroscópico de polpa de seriguela atomizada utilizando diferentes agentes carreadores de secagem. In: XX Congresso Brasileiro de Engenharia Química, Florianópolis, 2014. Disponível em: https://www.proceedings.blucher.com.br/articledetails/comportamento-higroscpico-de-polpa-deseriguela-atomizada-utilizando-diferentes-agentescarreadores-de-secagem-17110. Acesso em: 03/05/2021.

FREITAS, E. F. M. et al. Efeito da maltodextrina no sumo da polpa de abacaxi 'pérola' atomizado. Revista de Ciências Agrárias, v. 41, n. 1, p. 275282, 2019.

FRANCISQUINI, J. A. et al. Reação de maillard: uma revisão. Revista do Instituto de Laticínios Cândido Tostes, v. 72, n. 1, p. 48-57, 2017.

GERALDI, C. A. Q. et al. Estudo da cinética de secagem e caracterização físico-química da polpa de pitanga (Eugenia uniflora). In: Congresso Internacional da Agroindústria, I, 2020, Recife. Anais eletrônicos. Recife: Instituto Internacional
Despertando Vocações, 2020. Disponível em: https://ciagro.institutoidv.org/ciagro/uploads/1672.pd f. Acesso 03/05/2021.

GEROMEL, L. B.; FREITAS, I. R. Aplicação da energia de micro-ondas para secagem da banana nanica (Musa acuminata 'dwarf cavendish') submetida ao processo de osmose. Colloquium Exactarum, v. 12, n. 1, p.1-10, 2020.

GOMES, L. D. B. C.; ALMEIDA, E. M.; OLIVEIRA, S. N. Cinética de secagem em camada de espuma e caracterização física de acerola em pó. Revista brasileira de agrotecnologia, v. 7, n. 2, p. 178-184, 2017.

GONELI, A. L. D. et al. Modelagem matemática e difusividade efetiva de folhas de aroeira durante a secagem. Pesq. Agropec. Trop., v. 44, n. 1, p. 56 64, 2014.

IZLI, N.; IZLI, G.; TASKIN, O. Influence of different drying techniques on drying parameters of mango. Food Science and Technology, v. 37, n. 4, p. 604612, 2017.

KANDASAMY, P. et al. Preparation of papaya powder under foam-mat drying technique using egg albumin as foaming agente. International Journal of Bio-resource and Stress Management, v. 3, p. 32431, 2012.

LEAL, A. K.; GERALDI, C. A. Q.; KLASSEN, T. Influência da temperatura de secagem através do método de camada de espuma, na concentração de ácido ascórbicos, nas polpas dos frutos de abacaxi, acerola e carambola. In: XXI Congresso brasileiro de Engenharia Química, Fortaleza, 2016. Disponível em: https://proceedings.science/cobeq/cobeq2016/papers/influencia-da-temperatura-desecagem-atraves-do-metodo-de-camada-deespuma\%2C-na-concentracao-de-acidoascorbicos\%2C-nas-pol?lang=pt-br. Acesso em: 03/05/2021.

LEITE, D. D. F. et al. Avaliação da cinética de secagem da carambola em secador convectivo. Revista Verde de Agroecologia e Desenvolvimento Sustentável, v. 11, n. 2, p. 1-4, 2016.

LIMA, R. C. F; PEIXOTO, E. Z. H.; SARAIVA, S.H. Cinética de secagem do mamão formosa em secador de leito fixo. In: V Semana de Engenharia Química, V, 2017, Alegre. Anais eletrônicos. Alegre: Universidade Federal do Espírito Santo, 2017. Disponível em: https://www.proceedings.blucher.com.br/articledetails/cintica-de-secagem-do-mamo-formosa-emsecador-de-leito-fixo-25547. Acesso 03/05/2021.

LIMA, H. M. R.; LIMA, L. R.; GALVÃO, F. F. S. P. Consumo infantil de bebidas lácteas: sólidos solúveis totais (Brix) e pH. Odontologia ClínicoCientífica, v. 10, n. 3, p. 237-241, 2011. 
LOKHANDE, S. M.; RANVEER, R. C.; SAHOO, A. $\mathrm{K}$. Effect of microwave drying on textural and sensorial properties of grape raisins. International Journal of ChemTech Research, v. 10, n. 5, p. 938947, 2017.

MACIEL, R. M. G. et al., Cinética de secagem de polpa de goiaba em camada de espuma. In: Congresso Brasileiro de Ciência e Tecnologia dos Alimentos, XXV, 2016, Gramado. Anais eletrônicos. Gramado: Fundação de Apoio da Universidade Federal do Rio Grande do Sul, 2016. Disponível em: http://www.ufrgs.br/sbctars-

eventos/xxvcbcta/anais/files/131.pdf. Acesso em: 03/05/2021.

MARTINS, H. F. et al. Maracujá-amarelo (Passiflora edulis f. Flavicarpa): cinética da secagem artificial e natural da casca. Brazilian journal of development, v. 5, n. 10, p. 23234-23245, 2019.

MARQUES, G. M. R.; ARRUDA, R. S.; SILVA, A. A. L. Secagem de caldo de cana em leito de espuma e caracterização físico-química do produto. Brazilian Journal of Food Research, v. 7, n. 2, p. 16-29. 2016.

MARSANASCO, M. et al. Liposomes as vehicles for vitamins $E$ and $C$ : An alternative to fortify orange juice and offer vitamin $C$ protection after heat treatment. Food research international, v. 44, n. 9, p. 3039-3046, 2011.

MEDEIROS, R. A. B. et al. Influence of dual-stage sugar substitution pretreatment on drying kinetics and quality parameters of mango. LWT-Food Science and Technology, v. 67, p. 167-173, 2016.

MELO, K. S. et al. Secagem em camada de espuma da polpa do fruto do mandacaru: experimentação e ajustes de modelos matemáticos, Revista Caatinga, v. 26, n. 2, p. 10-17, 2013.

MENDONÇA JÚNIOR F. A. et al. Vitaminas: uma abordagem prática de uso na alimentação de ruminantes. Revista Agropecuária Científica no Semi-Árido, v. 06, n. 04, p. 01 - 16, 2010.

MORAIS, R. A. et al. Caracterização Química, física e tecnologia da farinha obtida a partir da casca de Buriti (Mauritia flexuosa L.), Brazilian Journal of Development, v. 5, n. 11, p. 23307-23322, 2019.

MOREIRA, D. H. F. et al. Análise da secagem de café em secador solar passivo direto. Brazilian Journal of Development, v. 5, n. 9, p. 16556-16573, 2019

NEVES, L. C. Manual pós-colheita da fruticultura brasileira. $1^{\circ}$ ed., Londrina, SciELO-EDUEL, 2018.

NUNES, J. S. et al. Influência da temperatura de secagem nas propriedades físico-química de resíduos abacaxi. Revista Agropecuária Técnica, v. 1, n. 1, p. 41-46, 2017.
OLIVEIRA, M. I. S. et al. Estabilidade da polpa de morango atomizada utilizando diferentes agentes carreadores. Brazilian Journal of Food Technology, v. 16, n. 4, p. 310-318, 2013.

ONWUDE, D. I. et al. Modeling the Thin-Layer Drying of Fruits and Vegetables: A Review. Comprehensive Reviews in Food Science and Food Safety, v. 15, p. 599-618, 2016.

ORIKASA, T. et al. Applicability of vacuum-microwave drying for tomato fruit based on evaluations of energy cost, color, functional components, and sensory qualities. Journal of food processing and preservation, v. 42, n. 6, 2018.

ÖZCAN, M. M. et al. Effect of microwave and oven drying processes on antioxidant activity, total phenol and phenolic compounds of kiwi and pepino fruits. Journal of food science and technology, v. 57, n. 1 , p. 233-242, 2019.

$\mathrm{PE}, \mathrm{P}$. R. et al., Secagem de polpa de caqui pelo método de camada de espuma. HOLOS, v. 4, p. 7785, 2016.

RESENDE, K. K. O. et al. Cinética de secagem e avaliação físico-química de fruta-pão (Artocarpus altilis) variedade seminífera. Revista de Agricultura Neotropical, v. 6, n. 1, p. 74-81, 2019.

RIGUETO, C. V. T. et al. Influência da temperatura de secagem de uvaia (Eugenia pyriformis) em camada de espuma, Engevista, v. 20, n. 4, p. 537547, 2018.

RIGUETO, C. V. T. et al. Influência da temperatura de secagem de jambo vermelho (Syzygium malaccense) em camada de espuma. Research, Society and Development, v. 9, n. 3, p. 40932382, 2020.

RIMOLI, P. A. R. et al. Avaliação da polpa de cajámanga submetida a secagem por atomização. In: $\mathrm{V}$ Congresso de Ensino, Pesquisa e Extensão da UEG: Ciência para redução de desigualdades, Pirenópolis: Universidade Estadual de Goiás, 2019. Disponível em: https://www.anais.ueg.br/index.php/cepe/article/view /12414. Acesso 03/05/2021.

RODRIGUES, F.; MARFIL, P. H. M. Efeito do tratamento osmótico nas propriedades mecânicas de fatias de abacaxi (Ananas comosus) desidratadas em secador de leito fixo. Revista Brasileira de Ciência, Tecnologia e Inovação, v. 5, n. 2, p. 87-97, 2020.

RODRIGUES, L. A.; FERREIRA, C. L. P.; BARROS, W. M. Desenvolvimento de biscoito do tipo cookie elaborado com composto farináceo com diferentes frutas secas. Revista Ciências Exatas e Naturais, v. xx, n. Xx, 2014. 
RODRIGUES, D. J.; GERALDI, C. A. Q.; LOSS, R. A. Secagem em camada de espuma e caracterização físico química da polpa de Guavira (Campomanesia adamantium). In: Congresso Internacional da Agroindústria, Recife, 2020. Disponível em: https://ciagro.institutoidv.org/ciagro/uploads/1972.pd f. Acesso 03/05/2021.

SANTOS, A. A. C. et al. Avaliação físico-química e comportamento higroscópico de goiaba em pó obtida por spray-dryer, Revista Ciência Agronômica, v. 45, n. 3, p. 508-514, 2014.

SANTOS, N. A. S. et al. Cinética de secagem de manga palmer desidratada em camada de espuma. In: 70a Reunião Anual da SBPCA. Maceió: Universidade Federal de Alagoas, 2018. Disponível em:

http://www.sbpcnet.org.br/livro/70ra/trabalhos/resum os/2609_1bec9ceefd6bac13897ece790f967adc5.pd fAcesso em 03/05/2021.

SILVA, A. G. P.; FARIA, L. J. G.; COSTA, C. M. L. Otimização do processo de secagem dos frutos do açaí (Euterpe oleracea Mart.) em secador de leito fixo. Blucher Chemical Engineering Proceedings, v. 1, n. 2, p. 5743-5750, 2014.

SILVA, D. I. S. et al. Changes of antioxidant constituents in pineapple (Ananas comosus) residue during drying process. Industrial Crops and Products, v. 50, p. 557-562, 2013.

SILVA, J. N. et al. Isoterma de sorção de uva arra $15 \AA$ desidratada e armazenada em diferentes embalagens. In: Congresso Internacional da Agroindústria, I, 2020, Recife. Anais eletrônicos. Recife: Instituto Internacional Despertando Vocações, 2020. Disponível em: https://ciagro.institutoidv.org/ciagro/uploads/1891.pd f. Acesso 03/05/2021.

SILVA, D. I. S.; SOUZA, G. F. M. V.; BARROZO, M. A. S. Heat and mass transfer of fruit residues in a fixed bed dryer: Modeling and product quality. Drying Technology. 2018. DOI: 10.1080/07373937.2018.1498509.

SILVA, D. V. et al. Qualidade nutricional das farinhas de epicarpo e mesocarpo de frutos de baru submetidos à secagem. Revista Brasileira de Engenharia Agrícola e Ambiental, v. 23, n.1, p. 6570, 2019.

SILVA, M. I. et al. Caracterização físico-química da polpa de umbu em camada de espuma. Revista Semiárido De Visu, v. 3, n. 2, p. 82-91, 2015.

SILVA JÚNIOR, M. E.; MORAIS, B. D. M.; MACIEL, M. I. S. Secagem por atomização de polpa de ciriguela (Spondias purpúrea L.): influência das variedades de processos e sua qualidade. In: Jornada de Ensino, Pesquisa e Extensão, XIII,
2013, Recife. Anais eletrônicos. Recife: Universidade Federal Rural de Pernambuco, 2013. Disponível em: http://www.eventosufrpe.com.br/2013/cd/resumos/R 0321-1.pdf. Acesso em: 03/05/2021.

SILVA, Q. J.; FIGUEIREDO, F. J.; LIMA, V. L. A. G. Características físicas e químicas de cirigueleiras cultivadas na Zona da Mata Norte de Pernambuco. Revista Ceres, v. 63, n. 3, p.285-290, 2016.

SOUSA, A. P. M. et al. Modelagem matemática da secagem de resíduo de acerola em forno de microondas. Brazilian Journal of Animal and Environmental Research, v. 3, n. 3, p. 1797-1806, 2020.

SOUZA, D. S. et al. Elaboração de farinha instantânea a partir da polpa de fruta-pão (Artocarpus altilis), Ciência Rural, v. 42, n. 6, p. 1123-1129, 2012.

SOUSA, F. C. et al. Secagem de resíduos de Spondias sp. em camada fina. Revista AGROTEC, v. 36, n. 1, p. 197-202, 2015.

SHIBAO, J.; BASTOS, D. H. M. Produtos da reação de Maillard em alimentos: implicações para a saúde. Revista de Nutrição, v. 24, n. 6, p. 895-904, 2011.

TELLES, E, O. Microrganismos deteriorantes, patogênicos e tecnológicos - fatores intrínsecos e extrínsecos. VPS 2012 - Higiene e Segurança Alimentar. 2012.

ULLMANN, G. et al. Avaliação do teor de compostos bioativos do resíduo de acerola (Malpighia emarginata D.C.) após secagem em leito fixo. In: Jornada em Engenharia Química, XIX, 2014, Uberlândia. Anais eletrônicos. Uberlândia: Universidade Federal de Uberlândia, 2014. Disponível em: http://www.peteq.feq.ufu.br/jorneq/anais2014/trabalh os/AL64.pdf. Acesso em 03/05/2021.

VARGAS, P. O. et al. Cinética de secagem de diferentes frutas com ar quente combinado com micro-ondas. In: Congresso brasileiro de Engenharia Química, XXI, 2016.. Disponível em: https://proceedings.science/cobeq/cobeq2016/papers/cinetica-de-secagem-de-diferentesfrutas-com-ar-quente-combinado-com-microondas\#: :text=Dentre\%20os\%20processos $\% 20 \mathrm{de} \%$ 20secagem,compara\%C3\%A7\%C3\%A30\%20com\% 20a\%20secagem\%20convectiva. Acesso em: 03/05/2021.

VIEIRA, A. H. et al. Armazenamento de pitanga em pó. Comunicata Scientiae, v. 5, n. 1, p. 83-91, 2014.

VIMERCATI, W. C. et al. Efeito da temperatura na cinética de secagem em leito de espuma e na 
degradação de antocianina em morango. Brazilian Journal of food technology, v. 22, p. 2018221, 2019.

WOJDYŁO, A. et al. Effect of convective and vacuum-microwave drying on the bioactive compounds, color, and antioxidant capacity of sour cherries. Food and Bioprocess Technology, v. 7, n. 3, p. 829-841, 2013. 